\title{
Mathematical Analysis of Different Noises for 3D Perfect Difference Codes based OCDMA System
}

\author{
Charu Singh and Gurjit Kaur* \\ Research Scholar, Thapar Institute of Engineering and Technology, Patiala, \\ Punjab, India E-mail: charusingh1301@gmail.com \\ *Assistant Professor, School of ICT, Gautam Buddha University, Greater Noida, \\ UP, India Email: gurjeet_kaur@rediffmail.com
}

\begin{abstract}
The perfect difference codes minimize the Phase Induced Intensity Noise (PIIN) and cancel the multiple access interference. Earlier researchers analyze the performance of OCDMA systems considering three noises namely PIIN, shot and thermal noise for $3 D$ Perfect Difference Codes (PDC) for OCDMA system. In this research paper we have considered two more noises i.e. $1 / f$ and generation recombination noise for $3 D P D C$ based OCDMA system. Mathematical analysis has been done and the performance of the system has been evaluated for higher data rates i.e. 1Gbps to 10Gbps for minimum BER $e^{-9}$.
\end{abstract}

Keywords: 3D Perfect Difference Codes (PDC), Optical Code Division Multiple Access (OCDMA), shot noise, thermal noise, PIIN, 1/f noise

\section{Introduction}

Optical code division multiple access system came into existence as it allows more number of users to access the channel simultaneously at high security. System performance is affected mainly by interference among adjacent users known as Multiple User Interface (MUI). Various researchers are working on 3D codes by considering noises. In [13] the authors analyze the performance of OCDMA systems considering three noises namely PIIN, shot and thermal noise.

In this research paper we have considered two more noises i.e. $1 / \mathrm{f}$ and generation recombination noise for $3 \mathrm{D}$ perfect difference codes. The $1 / \mathrm{f}$ noise occurs in almost all of the electronic devices and it increases without any limit as frequency decreases. 1/f noise alternately referred to as pink or flicker noise can be found in a wide range of systems. A $1 / \mathrm{f}$ power spectrum can arise from very different time traces (sharp bursts versus slower baseline drifts of the system). The origins of these noise sources are not the focus of this research. In the context of our analysis of performance evaluation, it is sufficient to quantitatively characterize $1 / \mathrm{f}$ noise based on empirical data without seeking the exact nature of the noise source. Interestingly, the typical noise characteristics specified for high sensitivity optical detectors, including the noise equivalent power reflect only the PIIN, shot and thermal noise. We note that such a characterization is incomplete, as the detector circuitry, among other potential sources, necessarily contributes dark 1/f noise. In the presence of dark 1/f noise, such devices will deviate from their predicted performance in which only dark white noise is accounted for. Our goal in this manuscript is to quantify this deviation. In particular, we will study the impact of dark 1/f noise on the receiver performance. Generation-Recombination noise is a type of electrical signal noise caused statistically by the fluctuation of the generation and recombination of electrons in the semiconductor-based photon detectors [14].

The performance has been evaluated for higher data rates i.e. $1 \mathrm{Gbps}, 2.5 \mathrm{Gbps}, 5 \mathrm{Gbps}$ and 10Gbps. The paper is organized as follows. Mathematical model of all the noises is 
described in Section II. The results are given in Section III. Finally, conclusion is explained in Section IV and future scope in section V followed by references.

\section{Mathematical Model}

3D PD codes are constructed using 1D PD codes [13].

The photocurrent is given by:

$$
\begin{gathered}
\left\langle\mathrm{i}_{\text {noise }}^{2}\right\rangle=\left\langle\mathrm{i}_{\text {PIIN }}^{2}\right\rangle+\left\langle\mathrm{i}_{\text {Shot }}^{2}\right\rangle+\left\langle\mathrm{i}_{\text {thermal }}^{2}\right\rangle \\
=\mathrm{I}_{\mathrm{r}} \mathrm{B}_{\mathrm{r}} \tau_{\mathrm{r}}+2 \mathrm{el}_{\text {total }} \mathrm{B}_{\mathrm{r}}+\frac{4 \mathrm{~K}_{\mathrm{b}} \mathrm{T}_{\mathrm{r}} \mathrm{B}_{\mathrm{r}}}{\mathrm{R}_{\mathrm{l}}}
\end{gathered}
$$

Where, $l_{r}$ and $l_{\text {total }}$ are the average and the total photocurrents, which will be derived latter. $B_{r}$ is the electrical bandwidth, $\tau_{r}$ is the coherence time of the light incident to the photodiode, e is electron's charge, $K_{b}$ is Boltzmann's constant, $T_{r}$ is the absolute noise temperature, and $\mathrm{R}_{\mathrm{L}}$ is the load resistance.

Variance of PIIN is given by

$$
<\mathrm{i}_{\text {PIIN }}^{2}>=\frac{\mathrm{MB}_{\mathrm{r}}}{2 \Delta \mathrm{f}}\left\{\frac{\left(\mathrm{I}_{0}-\mathrm{I}_{1}-\mathrm{I}_{4}+\mathrm{I}_{5}\right)^{2}}{\mathrm{~K}_{1}}+\frac{\left(\mathrm{I}_{2}-\mathrm{I}_{3}-\mathrm{I}_{6}+\mathrm{I}_{7}\right)^{2}}{\left(\mathrm{~K}_{1}-1\right)^{2}}\right\}
$$

Variance of shot noise is given by:

$$
\begin{aligned}
< & \mathrm{i}_{\text {shot }}^{2}>=\mathrm{eB}_{\mathrm{r}} \mathrm{I}_{\text {total }} \\
= & \mathrm{eB} \mathrm{B}_{\mathrm{r}}\left(\mathrm{I}_{0}+\mathrm{I}_{1}+\mathrm{I}_{2}+\mathrm{I}_{4}+\mathrm{I}_{5}+\mathrm{I}_{6}+\mathrm{I}_{7}\right) \\
& \text { Variance of thermal noise is given by: }
\end{aligned}
$$

$<\mathrm{i}_{\text {thermal }}^{2}>=\frac{4 \mathrm{~K}_{\mathrm{b}} \mathrm{T}_{\mathrm{n}} \mathrm{B}_{\mathrm{r}}}{\mathrm{R}_{\mathrm{L}}}$

We have considered two more noises i.e. 1/f and generation recombination noises to further evaluate the performance of OCDMA system.

Variance of $1 / \mathrm{f}$ noise is given by:

Value of $\mathrm{t}=2$

$$
<\mathrm{i}_{1 / \mathrm{f}}^{2}>=\frac{\mathrm{t}^{2} \mathrm{I}_{\text {Total }}^{2} \Delta \mathrm{f}}{\mathrm{f}}
$$

Variance of generation recombination noise is given by:

$$
<\mathrm{i}_{\mathrm{g}-\mathrm{r}}^{2}>=4 \eta \mathrm{q}^{2} \mathrm{R}^{2} \mathrm{hf} \Delta \mathrm{f}
$$

where, $\eta$ is efficiency, $q$ is electron charge, $R$ is photoconductive gain, $h$ is Planck's constant, $f$ is frequency.

$$
\begin{aligned}
& I_{0}=\frac{R_{S r}}{K_{3} K_{2} M}\left\{K_{1} K_{2} K_{3}+\frac{K_{2} K_{1}(W-1)(P-1)}{(M N P-1)}+\frac{K_{1} K_{3}(W-1)(N-1)}{(M N P-1)}\right. \\
& +\frac{\mathrm{K}_{1}(\mathrm{~W}-1)(\mathrm{N}-1)(\mathrm{P}-1)}{(\mathrm{MNP}-1)}+\frac{\mathrm{K}_{2} \mathrm{~K}_{3}(\mathrm{~W}-1)(\mathrm{M}-1)}{(\mathrm{MNP}-1)} \\
& +\frac{\mathrm{K}_{2}(\mathrm{~W}-1)(\mathrm{M}-1)(\mathrm{P}-1)}{(\mathrm{MNP}-1)}+\frac{\mathrm{K}_{3}(\mathrm{~W}-1)(\mathrm{M}-1)(\mathrm{N}-1)}{\mathrm{MNP}-1)} \\
& \left.+\frac{(\mathrm{W}-1)(\mathrm{M}-1)(\mathrm{N}-1)(\mathrm{P}-1)}{(\mathrm{MNP}-1)}\right\} \\
& I_{1}=\frac{\mathrm{RP}_{\mathrm{sr}}}{\mathrm{K}_{3} \mathrm{~K}_{2} \mathrm{M}}\left\{\frac{\mathrm{K}_{1} \mathrm{~K}_{3}(\mathrm{~W}-1)(\mathrm{N}-1)}{(\mathrm{MNP}-1)}+\frac{\mathrm{K}_{1}(\mathrm{~W}-1)(\mathrm{N}-1)(\mathrm{P}-1)}{(\mathrm{MNP}-1)}\right. \\
& +\frac{\mathrm{K}_{3}(\mathrm{~W}-1)(\mathrm{M}-1)(\mathrm{N}-1)}{\mathrm{MNP}-1)} \\
& \left.+\frac{(\mathrm{W}-1)(\mathrm{M}-1)(\mathrm{N}-1)(\mathrm{P}-1)}{(\mathrm{MNP}-1)}\right\}
\end{aligned}
$$




$$
\begin{gathered}
I_{2}=\frac{R P_{s r}}{K_{3} K_{2} M}\left\{\frac{K_{2} K_{3}(\mathrm{~W}-1)(P-1)}{(M N P-1)}+\frac{K_{2}(\mathrm{~W}-1)(\mathrm{M}-1)(\mathrm{P}-1)}{(\mathrm{MNP}-1)}\right. \\
+\frac{\mathrm{K}_{3}(\mathrm{~W}-1)(\mathrm{M}-1)(\mathrm{N}-1)}{\mathrm{MNP}-1)} \\
\left.\quad+\frac{(\mathrm{W}-1)(\mathrm{M}-1)(\mathrm{N}-1)(\mathrm{P}-1)}{(\mathrm{MNP}-1)}\right\} \\
\mathrm{I}_{3}=\frac{\mathrm{RP}_{\mathrm{sr}}}{\mathrm{K}_{3} \mathrm{~K}_{2} \mathrm{M}}\left\{\frac{\mathrm{K}_{3}(\mathrm{~W}-1)(\mathrm{M}-1)(\mathrm{N}-1)}{\mathrm{MNP}-1)}+\frac{(\mathrm{W}-1)(\mathrm{M}-1)(\mathrm{N}-1)(\mathrm{P}-1)}{(\mathrm{MNP}-1)}\right\} \\
\mathrm{I}_{4}=\frac{\mathrm{RP}_{\mathrm{sr}}}{\mathrm{K}_{3} \mathrm{~K}_{2} \mathrm{M}}\left\{\frac{\mathrm{K}_{2} \mathrm{~K}_{1}(\mathrm{~W}-1)(\mathrm{P}-1)}{(\mathrm{MNP}-1)}+\frac{\mathrm{K}_{2}(\mathrm{~W}-1)(\mathrm{M}-1)(\mathrm{P}-1)}{(\mathrm{MNP}-1)}\right. \\
\left.+\frac{\mathrm{K}_{1}(\mathrm{~W}-1)(\mathrm{P}-1)(\mathrm{N}-1)}{\mathrm{MNP}-1)}+\frac{(\mathrm{W}-1)(\mathrm{M}-1)(\mathrm{N}-1)(\mathrm{P}-1)}{(\mathrm{MNP}-1)}\right\} \\
\mathrm{I}_{5}=\frac{\mathrm{RP}_{\mathrm{sr}}}{\mathrm{K}_{3} \mathrm{~K}_{2} \mathrm{M}}\left\{\frac{\mathrm{K}_{1}(\mathrm{~W}-1)(\mathrm{P}-1)(\mathrm{N}-1)}{\mathrm{MNP}-1)}+\frac{(\mathrm{W}-1)(\mathrm{M}-1)(\mathrm{N}-1)(\mathrm{P}-1)}{(\mathrm{MNP}-1)}\right\} \\
\mathrm{I}_{6}=\frac{\mathrm{RP}_{\mathrm{sr}}}{\mathrm{K}_{3} \mathrm{~K}_{2} \mathrm{M}}\left\{\frac{\mathrm{K}_{2}(\mathrm{~W}-1)(\mathrm{P}-1)(\mathrm{M}-1)}{\mathrm{MNP}-1)}+\frac{(\mathrm{W}-1)(\mathrm{M}-1)(\mathrm{N}-1)(\mathrm{P}-1)}{(\mathrm{MNP}-1)}\right\} \\
\mathrm{I}_{7}=\frac{\mathrm{RP}}{\mathrm{K}_{3} \mathrm{~K}_{2} \mathrm{M}}\left\{\frac{(\mathrm{W}-1)(\mathrm{M}-1)(\mathrm{N}-1)(\mathrm{P}-1)}{(\mathrm{MNP}-1)}\right\}
\end{gathered}
$$

Consequently SNR is given as:

$$
\begin{aligned}
& \mathrm{SNR}=\frac{\mathrm{I}_{\mathrm{r}}^{2}}{\left\langle\mathrm{i}_{\text {PIN }}^{2}>+<\mathrm{i}_{\text {Shot }}^{2}>+<\mathrm{i}_{\text {thermal }}^{2}>\right.} \\
& +<i_{1 / \mathrm{f}}^{2}>+<\mathrm{i}_{\mathrm{g}-\mathrm{r}}^{2}>
\end{aligned}
$$

Using the values of $I_{0}$ to $I_{7}$ variance of noises is calculated and furthermore, the BER can then be estimated from SNR.

$$
\mathrm{BER}=\frac{\operatorname{erfc}\left(\sqrt{\frac{\mathrm{SNR}}{8}}\right)}{2}
$$

Where,

$$
\operatorname{erfc}(\mathrm{x})=\frac{2}{\sqrt{\pi}} \int_{\mathrm{x}}^{\infty} \exp \left(-\mathrm{z}^{2}\right) \mathrm{dz}
$$

The design parameters are listed as follows in table 1 .

Table 1. Parameters

\begin{tabular}{|c|l|l|}
\hline S.No. & Parameters & Value \\
\hline 1 & Efficiency & $\Pi=0.6$ \\
\hline 2 & Spectral width & $\Delta \lambda=40 \mathrm{~nm}$ \\
\hline 3 & Wavelength Location & $1.55 \mu \mathrm{m}$ \\
\hline 4 & Data Transmission Rate & $1 \mathrm{Gbps}, 2.5 \mathrm{Gbps}, 5 \mathrm{Gbps}$ and $10 \mathrm{Gbps}$ \\
\hline 5 & Noise Temperature & $\mathrm{T}=300 \mathrm{~K}$ \\
\hline 6 & Receiver resistor & $\mathrm{R}=1030 \Omega$ \\
\hline 7 & Power & $-70 \mathrm{dbm}$ to $10 \mathrm{dbm}$ \\
\hline 8 & Code set $(\mathrm{M}, \mathrm{N}, \mathrm{P})$ & $(3,21,3),(7,21,3),(13,21,3) \&$ \\
& & $(3,21,7),(3,31,7),(7,21,7)$ \\
\hline 9 & Electron charge & $1.6 \times 10^{\wedge}-19$ \\
\hline 10 & Planck's constant & $6.623 \times 10^{\wedge}-34$ \\
\hline 11 & Frequency & $1.93 \times 10^{\wedge} 14 \mathrm{~Hz}$ \\
\hline
\end{tabular}


$\mathrm{M}, \mathrm{N}, \mathrm{P}$ used in above equations are three parameters that define the code sets of 3D perfect difference codes. $\mathrm{M}$ implies spectral code length, $\mathrm{N}$ is time spreading code length and $\mathrm{P}$ is spatial code length.

\section{Results}

The analysis has been done for various numbers of users for BER $\mathrm{e}^{-9}$. Even the performance has been analyzed for minimum received power i.e. $10 \mathrm{dBm}$ to $-70 \mathrm{dBm}$. Code set considered are $(3,21,3),(7,21,3),(13,21,3)$ and $(3,21,7),(3,31,7),(7,21,7)$.

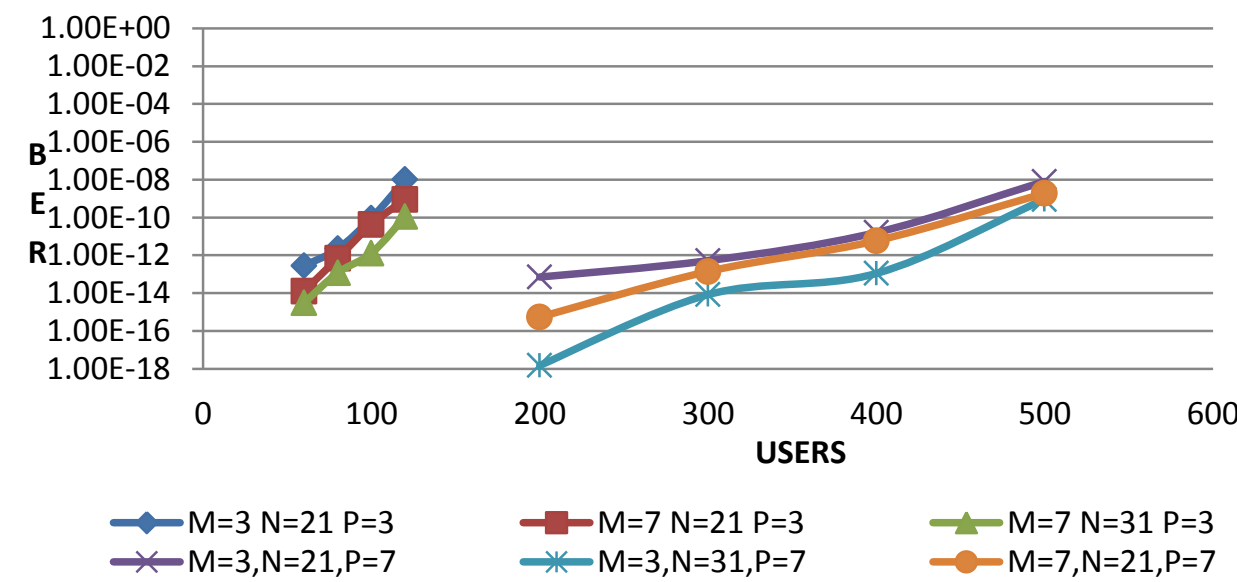

Figure 1. Number of Users vs BER at $1 \mathrm{Gbps}$, power is $-10 \mathrm{dBm}$

Initially, results are obtained in Figures 1, 2 and 3 for the number of users versus BER. Received power is set to $-10 \mathrm{dBm}$. Noises considered while result analysis are PIIN, shot, thermal, $1 / \mathrm{f}$ and generation recombination noise. Data rate considered is $1 \mathrm{Gbps}$ in figure $1,5 \mathrm{Gbps}$ in figure 2 and $10 \mathrm{Gbps}$ in figure $3 . \mathrm{M}, \mathrm{N}$ and $\mathrm{P}$ are spectral, time spreading and spatial code length of $3 \mathrm{D}$ perfect difference code set respectively.

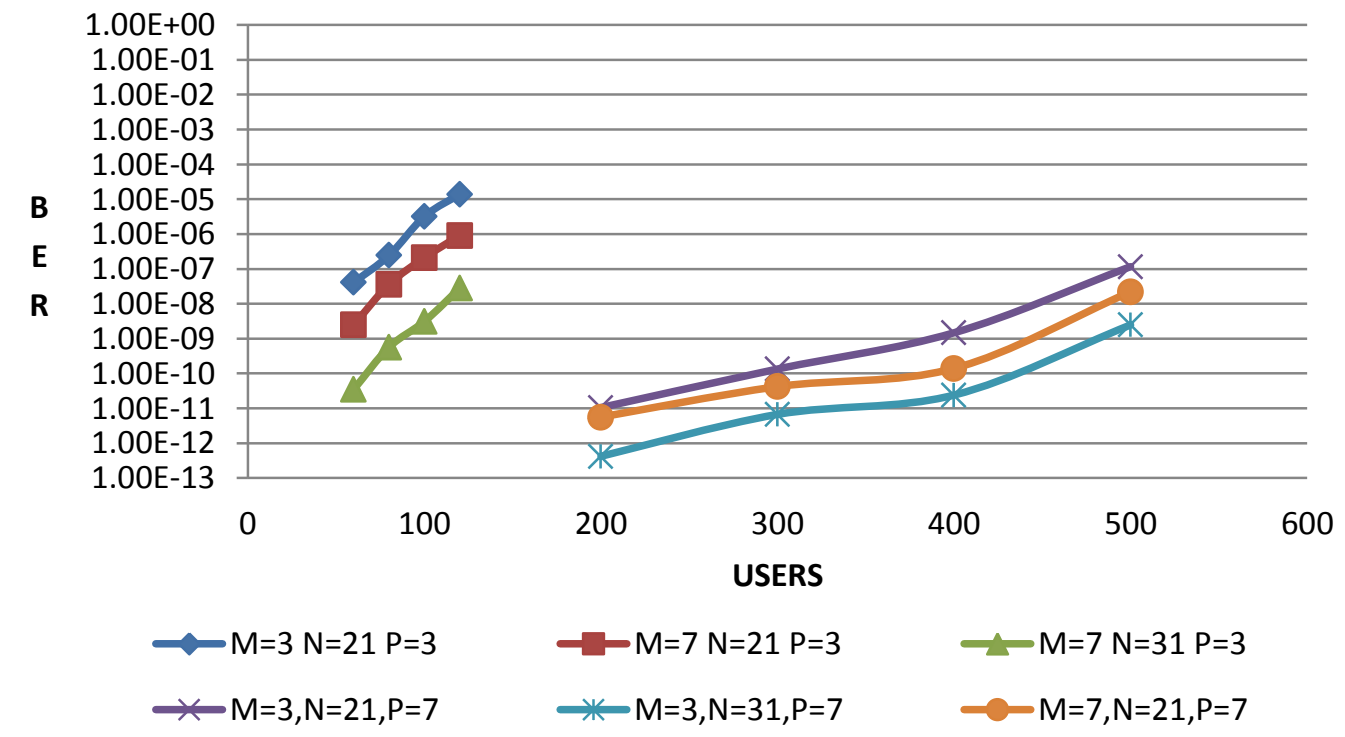

Figure 2. Number of Users vs BER at $5 \mathrm{Gbps}$ power is $-10 \mathrm{dbm}$

It is analyzed that as spatial code length increases as the number of users increases. Though increasing data rate increases the value of BER also but to meet with high pacing 
technology higher data rates has to be switched over. At 1 Gbps code set $(3,21,7),(3,31,7)$, $(7,21,7)$ can support 100 more users as compared to code set $(3,21,3),(7,21,3),(13,21,3)$. With increasing data rate from $1 \mathrm{Gbps}, 5 \mathrm{Gbps}$ to $10 \mathrm{Gbps}$ the BER has been increased from e-18 to e-11 for $(7,21,7)$ and e-15 to e-9 for $(7,31,3)$.

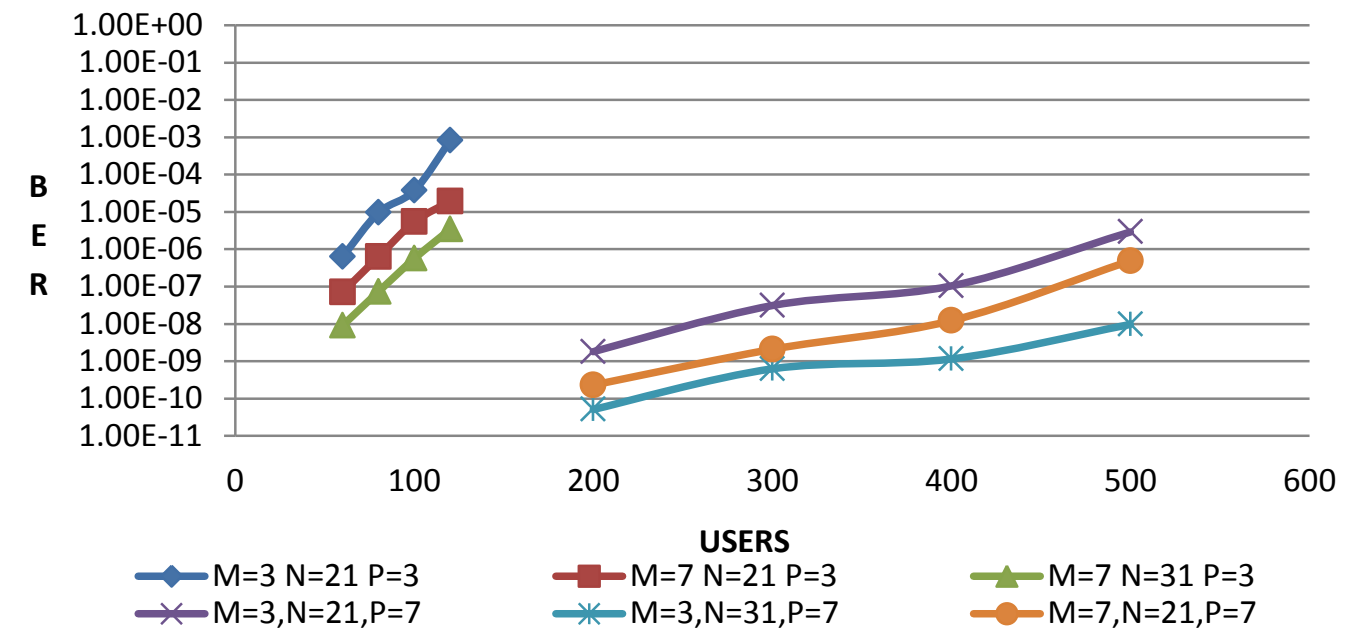

Figure 3: Number of Users vs BER at $10 \mathrm{Gbps}$ for power $-10 \mathrm{dBm}$

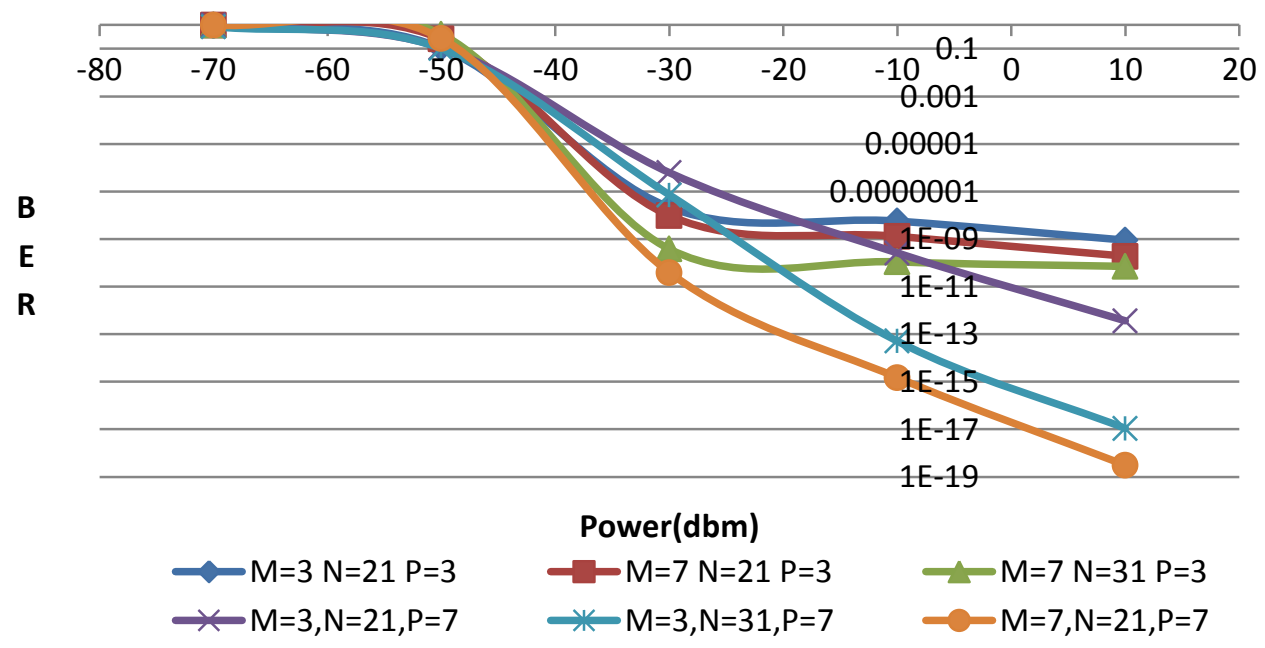

Figure 4. Power (dBm) vs BER at $1 \mathrm{Gbps}$

So we have done the calculation for different number of users versus BER with received power fixed to $-10 \mathrm{dBm}$. Now, the number of users are fixed to 117 for $(3,21,3)$, $(7,21,3),(13,21,3)$ and 300 for $(3,21,7),(3,31,7),(7,21,7)$ whereas received power is varied from $10 \mathrm{dBm}$ to $-70 \mathrm{dBm}$.

Figure 4, 5 and 6 shows the power in $\mathrm{dBm}$ versus BER for $1 \mathrm{Gbps}, 5 \mathrm{Gbps}$ and $10 \mathrm{Gbps}$ respectively. It is analyzed that with increased value of spatial code length i.e. BER is improved. Though increasing the value of spectral and time spreading code length also gives improved results but increased value of $\mathrm{P}$ yields better results. 


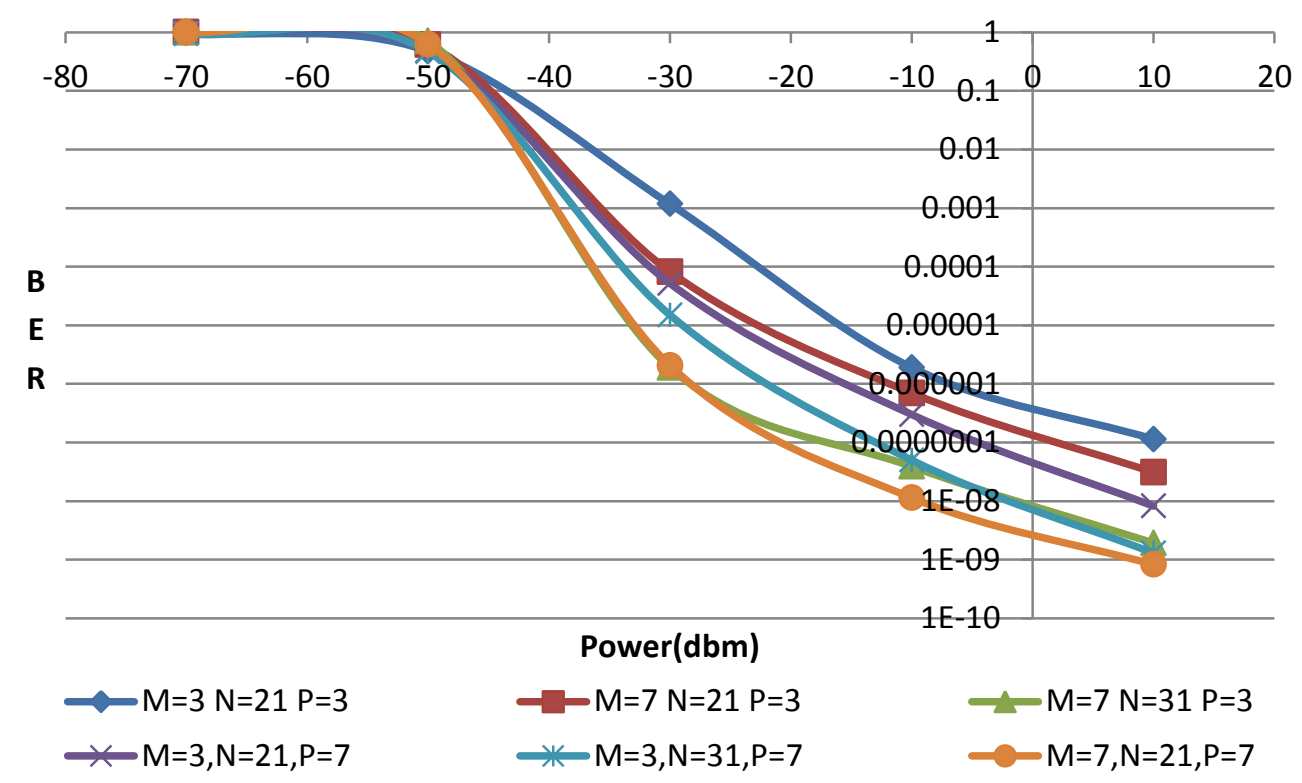

Figure 5. Power (dBm) vs BER at 5Gbps

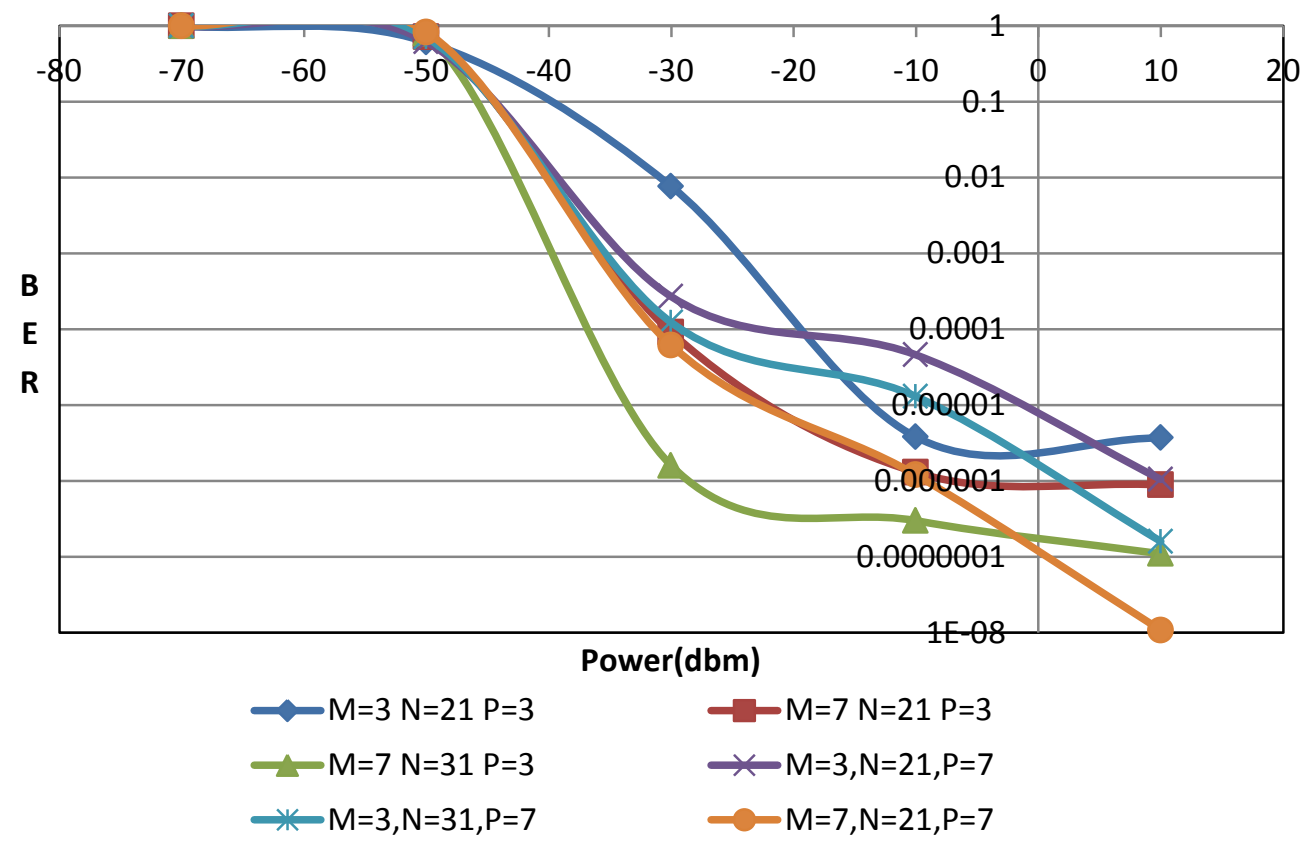

Figure 6. Power (dBm) vs BER at $10 \mathrm{Gbps}$

Table 2 gives an overview of number of users supported by OCDMA system at different data rates considering three noises (PIIN, shot and thermal noise) and five noises (PIIN, shot, thermal, 1/f and generation recombination noise).

Table 2. Result Tabulation

\begin{tabular}{|l|l|l|l|l|}
\hline $\begin{array}{l}\text { Data Rate } \\
\text { (Gbps) }\end{array}$ & \multicolumn{2}{|l|}{$\begin{array}{l}\text { ( PIIN, shot and thermal noise) } \\
\text { (Users Supported) }\end{array}$} & \multicolumn{2}{|l|}{$\begin{array}{l}\text { (PIIN, shot, thermal, 1/f and generation } \\
\text { recombination noise) (Users Supported) }\end{array}$} \\
\hline Code Set & $\begin{array}{l}(3,21,3), \\
(7,21,3),\end{array}$ & $\begin{array}{l}(3,21,7), \\
(3,31,7),\end{array}$ & $\begin{array}{l}(3,21,3), \\
(7,21,3),\end{array}$ & $(3,21,7)$, \\
& $(3,31,7)$, \\
\hline
\end{tabular}




\begin{tabular}{|l|l|l|l|l|}
\hline & $(13,21,3)$ & $(7,21,7)$ & $(13,21,3)$ & $(7,21,7)$ \\
\hline 1 Gbps & $\begin{array}{l}110,120, \text { more } \\
\text { than } 125\end{array}$ & $425,500,440$ & $\begin{array}{l}100,110, \text { more than } \\
115\end{array}$ & $400,480,435$ \\
\hline $2.5 \mathrm{Gbps}$ & $78,80,95$ & $365,420,382$ & $70,80,90$ & $360,400,325$ \\
\hline $5 \mathrm{Gbps}$ & $70,85,90$ & $180,300,240$ & $45,60,85$ & $165,280,220$ \\
\hline $10 \mathrm{Gbps}$ & $45,60,75$ & 175 & $35,55,75$ & 160 \\
\hline
\end{tabular}

\section{Conclusion}

Results are obtained in various forms for various data rate and power. With high speeding technology our aim is to accommodate more and more number of users at higher data rates. Though as data rate is enhanced BER is increased but to increase the number of users is also necessary so a trade off is required. All noises considered which exists in the electronic devices so they will play an important role as OCDMA utilizes number of electronic devices. Some noise exists on receiver side while some on transmitter side. There are noise that exists on both the receiver as well as transmitter side. It is analyzed from results that increasing the value of $\mathrm{P}$ gives better results. It means that increasing the spatial encoding implementation complexity can greatly improve the system performance. However, unfortunately, increasing the spatial code length $\mathrm{P}$ is the most difficult part practically. It is because that the numbers of fibers and star couplers will be increased in proportion to the spatial code length $\mathrm{P}$. If the spatial code length and the value of $\mathrm{MN}$ are fixed, increasing the time-spreading code length $\mathrm{N}$ yields better performance than increasing the spectral code length $\mathrm{M}$. However it needs more high speed electronics. With $(3,21,7),(3,31,7),(7,21,7)$ system can accommodate 100 more users in the system. For better performance, system will be cost effective but it will support more users and yields better results. In future, data rate can be increased beyond $10 \mathrm{Gbps}$. In this paper only one type of codes i.e. 3D Perfect difference codes are considered. System can be modeled for orthogonal or some other codes. Even code set can be increased.

\section{References}

[1] P. R. Prucnal, M. A. Santoro, and T. R. Fan, "Spread spectrum fiberoptic local area network using optical processing", J. Lightwave Technology, vol. , no. 5, (1986), pp. 547-554.

[2] W. C. Kwong, P. A. Perrier, and P. R. Prucnal, "Performance comparison of asynchronous and synchronous code-division multiple-access techniques for fiber-optic local area networks," IEEE Transactions on Communication, vol. 39, no. 11, (1991), pp. 1625-1634.

[3] C.-S. Weng and J. Wu, "Perfect difference codes for synchronous fiberoptic CDMA communication systems," Journal of Lightwave Technology, vol. 19, no. 2, (2001), pp. 186-194.

[4] J. A. Salehi, "Code division multiple-access techniques in optical fiber networks-Part I: Fundamental principles," IEEE Transactions on Communication, vol. 37, no. 8, (1989), pp. 824-833.

[5] F. R. K. Chung, J. A. Salehi, and V. K. Wei, "Optical orthogonal codes: Design analysis, and applications," IEEE Trans. Inf. Theory, vol. 35, no. 3, (1989), pp. 595-604.

[6] H. Fathallah, L. A. Rusch, and S. LaRochelle, "Passive optical fast frequency-hop CDMA communications system," Journal of Lightwave Technology vol.17, no. 3, (1999), pp. 397-405.

[7] E. Inaty, H. M. H. Shalaby, and P. Fortier, "On the cutoff rates of a multiclass OFFH-CDMA system," IEEE Transactions on Communication, vol. 53, no. 2, (2005), pp. 323-334.

[8] M. Kavehrad and D. Zaccarin, "Optical code-division-multiplexed systems based on spectral encoding of noncoherent sources," Journal of Lightwave Technology, vol. 13, no. 3, (1995), pp. 534-545.

[9] E. D. J. Smith, R. J. Blaikie, and D. P. Taylor, "Performance enhancement of spectral amplitude-coding optical CDMA using pulse-position modulation," IEEE Transactions on Communication, vol. 46, no. 3, (1998), pp. 1176-1185.

[10] X. Zhou, H. H. M. Shalaby, C. Lu, and T. Cheng, "Code for spectral amplitude coding optical CDMA systems," Electron. Lett., vol. 36, no.8, (2000), pp. 728-729.

[11] Z. Wei, H. M. H. Shalaby, and H. Ghafouri-Shiraz, "Modified quadratic congruence codes for fiber Bragg-grating-based spectral-amplitudecoding optical CDMA systems," Journal of Lightwave Technology.,vol. 19, no. 9, (2001), pp. 1274-1281.

[12] C.-C. Yang and J.-F. Huang, "Two-dimensional M-matrices coding in spatial/frequency optical CDMA networks,” IEEE Photon. Technol. Lett., vol. 15, no. 1, (2003), pp. 168-170. 
International Journal of Signal Processing, Image Processing and Pattern Recognition Vol.8, No.7 (2015)

[13] B. C. Yeh, C. H. Lin and J. Wu,“" Noncoherent Spectral/Time/Spatial Optical CDMA System Using 3D Perfect Defference Codes”, Journal of Lightwave Technology, vol. 27, no. 6, (2009) pp. 744-759. 